\title{
PLANTEAMIENTOS DE FREIRE Y SU IMPLICANCIA EN LA EDUCACIÓN SUPERIOR
}

\section{ABORDAGENS DE FREIRE E SUA IMPLICAÇÃO NA EDUCAÇÃO SUPERIOR}

\author{
VAZQUEZ, Marisa Ines ${ }^{1}$
}

\section{RESUMEN}

Próximo a veinte años de la desaparición física de Paulo Freire, su legado sigue vigente por las implicancias que tiene el sentido de sus concepciones y porque aún hoy necesita ser revisitado, recreado, en forma constante en la búsqueda de la mejora del trabajo cotidiano en la práctica docente y de las propuestas educativas. No resultó fácil determinar una categoría o un aspecto de la teoría de Freire para desarrollar, dado que su pensamiento se constituye con su práctica y forma un todo significativo. Todo lo que le concierne es de interés y nos sugiere e inspira; su biografía, sus experiencias y su producción se sostienen desde la coherencia e integración; por ello elijo lo relacionado con su proyección futura y lo analizo en relación con el impacto que tiene en la práctica docente. La idea que aquí se desarrollará consiste en recuperar desde una perspectiva crítica algunos aportes de Paulo Freire, y a partir de los mismos organizar y exponer los planteamientos que podrían tenerse en cuenta, en tal sentido, en la formación docente en el ámbito de Educación Superior. El desafío consiste en implementar un modelo de formación docente que logre superar efectivamente las contradicciones del sistema de opresión. Poder encontrar la puerta de entrada para pensar las prácticas educativas y la formación docente; desafiar para asumirse como sujetos dialógicos, políticos y cognoscentes; desafiar para caminar por el sendero de la educación pública, de calidad, democrática, tolerante y dialógica. Tengo en claro, aunque no sea fácil, que a Paulo Freire no lo debemos repetir, más bien reinventarlo, recrearlo; ya que esa es su mayor enseñanza. Y esto es fundamental como punto de partida, por cuanto encierra la esperanza de reinventarnos a nosotros mismos. Nuestro mejor anclaje está en el itinerario de su práctica educativa, las experiencias de su existencia y los saberes indecisos por ella gestados.

PALABRAS ClAVES: Práctica; Formación docente; Conocimiento; Educando; Educador

\section{RESUMO}

Próximo a vinte anos do desaparecimento físico de Paulo Freire, seu legado segue vigente pelas implicações que tem o sentido de suas concepções e porque ainda hoje precisa ser revisitado, recriado, em forma constante na busca da melhoria do trabalho cotidiano na prática docente e das propostas educativas. Não foi fácil determinar uma categoria ou um aspecto da teoria de Freire para desenvolver, dado que seu pensamento se constitui com sua prática e forma um todo significativo. Tudo o que se concerne a ele é de interesse e nos sugere e inspira; sua biografia, suas experiências e sua produção se sustentam pela coerência e integração; por isso, escolho o que se refere à sua projeção futura e o analiso

1 Maestra Normal Superior; Instituto Superior de Formación Docente y Tecnica. e-mail: marisavazz@yahoo.com.ar 


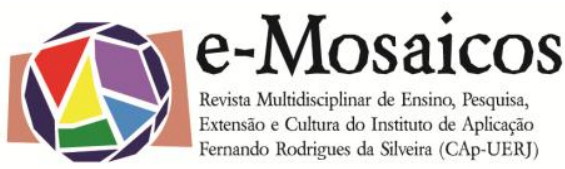

DOI: $10.12957 /$ e-mosaicos.2017.30816

em relação ao impacto que tem na prática docente. A ideia que aqui se desenvolverá consiste em recuperar a partir de perspectiva crítica algumas contribuições de Paulo Freire, e a partir destas, organizar e expor as propostas que poderiam ser consideradas, em tal sentido, na formação docente no âmbito da Educação Superior. O desafio consiste em implementar um modelo de formação docente que consiga superar efetivamente as contradições do sistema de opressão. Poder encontrar a porta de entrada para pensar as práticas educativas e a formação docente; desafiar para assumir-se como sujeitos dialógicos, políticos e cognoscentes; desafiar para caminhar pelo caminho da educação pública, de qualidade, democrática, tolerante e dialógica. Tenho em vista, embora não seja fácil, que não devemos repetir Paulo Freire, mas sim reinventá-lo, recriá-lo, já que esse é seu maior ensinamento. $E$ isto é fundamental como ponto de partida, por quanto encerra a esperança de reinventar-nos. Nossa melhor ancoragem está no itinerário de sua prática educativa, as experiências de sua existência e os saberes indecisos por ela gestados.

PalaVRAS-ChaVe: Prática; Formação docente; Conhecimento; Educando; Educador

Al entrar en un aula de educación superior, en las conversaciones recurrentes con la alumnas, en los trabajos compartidos con los profesores, en las jornadas de intercambio y en la observación de algunas actividades me surge un interrogante constante, ¿qué sucede en las aulas de los institutos de Formación docente que no les permite a los alumnos desarrollar de manera óptima su práctica docente?; o quizás la pregunta correcta sería: ¿Qué no hacemos en las aulas para que esto no suceda? ; O quizás el mejor cuestionamiento sería ¿Qué tenemos que hacer para que lo mejor suceda?.

Y así, casi mágicamente, vienen a mí diferentes frases del "maestro" Paulo Freire, que atraviesan las propuestas pedagógicas en un ideario de mejor escuela y que se entrecruzan con la realidad cotidiana en un intento de mejora, en este esfuerzo por encontrar pistas para contribuir a los cambios que beneficien la enseñanza.

Tal vez, una de las enseñanzas más importantes de Paulo Freire es su invitación a no caer ni en el optimismo ingenuo, ni en el escepticismo negativo de la educación y sus posibilidades. Esta convocatoria nos ayuda a mantener la utopía. Por tal motivo su teoría es pedagógica. Es una pedagogía para la transformación de la formación docente.

Las nociones de conocimiento, educando y educador conforman categorías clave en la pedagogía de Paulo Freire, y es a partir del tratamiento de ellas que se realiza esta propuesta para repensar la formación docente.

Reflexionar desde estas categorías, entendiéndolas como herramientas epistemológicas, implica realizar una reflexión acerca de las situaciones concretas de la realidad para problematizarlas, desnaturalizarlas y resignificarlas.

Uno de los principales planteos que hace Freire se refiere al conocimiento, y en este sentido sostiene que el mismo no se transmite sino que se construye 0 


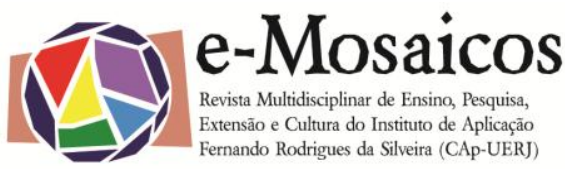

DOI: 10.12957/e-mosaicos.2017.30816

produce, y que tanto educando como educador deben percibirse y asumirse como sujetos activos en este proceso de construcción. Su pensamiento crítico fue claro en cuanto que debemos tomar la realidad como punto de partida del acto de conocer. Por eso plantea que enseñar no es transferir conocimientos, sino crear las posibilidades de su construcción o de su producción.

Se vuelve necesario en la formación docente no reducir la tarea docente a enseñar contenidos, sino que el desafío radica en enseñar y aprender a pensar correctamente.

Esto requiere que el o la docente, al enseñar, respete los saberes del educando: los respete y aproveche para los procesos de enseñanza y de aprendizaje y discuta con los estudiantes la razón de esos saberes en relación con la enseñanza de los contenidos. Freire criticó la transmisión autoritaria y memorística de los contenidos.

Su pensamiento está profundamente cimentado en el concepto de libertad, concepto que pone al servicio de la transformación de los procesos educativos y sociopolíticos. Freire busca que las y los estudiantes y las y los docentes dejen de ser objetos pasivos de una historia estática y dogmática, para convertirse en sujetos responsables, capaces de conocer y de crear su propia historia.

En este sentido, es imprescindible resignificar en las aulas la concepción de conocimiento que se construye en ellas, entendiéndolo como una construcción que es posible a partir del diálogo. El dialogo entendido como la posibilidad de dar voz a todas las personas, pues todas las personas tenemos siempre algo que decir y algo que aportar.

Ante esta situación, nuevamente surgen interrogantes: si tal como plantea Freire la existencia del diálogo sólo se puede dar si tenemos una profunda fe en el ser humano, en su poder de hacer y de rehacer, ¿qué concepción manejamos los docentes respecto de la naturaleza de nuestros estudiantes? ¿Estamos convencidos de que nuestros estudiantes tienen capacidad para hacer y rehacer, o simplemente pensamos que hay que darles las cosas hechas para que aprendan imitando?

Desde mis propias concepciones, considero que las y los estudiantes pueden y deben ser mirados como personas responsables, creativas, capaces de imponerse retos y de alcanzarlos, que tienen una vivencia que enriquece el proceso educativo. Desde esta óptica trato de orientar mis actuaciones docentes, entendiendo que se hace necesario reflexionar continuamente y modificar las practicas de acuerdo a las necesidades de los estudiantes y de los procesos de enseñanza y de aprendizaje que se vivencian en las aulas de los institutos de formación docente; teniendo como sustento la construcción de un sujeto diferente, que no es ni oprimido ni opresor, sino que puede ser un hombre nuevo, que se libere en forma permanente, que pueda enseñar y aprender al enseñar.

Así, partir de los saberes de los educandos "partiendo del sujeto oprimido, pero no para quedarse, sino justamente para partir a otro lugar" (FREIRE, 2006, p. 


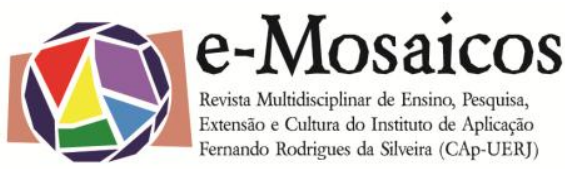

DOI: $10.12957 /$ e-mosaicos.2017.30816

67); la tarea docente debe estar centrada en la estimulación de la pregunta y la reflexión crítica sobre la propia pregunta. O, al decir del propio Freire, "lo que importa es que profesores y alumnos se asuman epistemológicamente curiosos" (FREIRE, 1997).

En el proceso de formación docente, la unidad entre el hacer, el pensar y el decir se torna problemática; más aún si se tienen en cuenta las contradicciones existentes entre la teoría y la práctica.

Freire da importancia a la reflexión crítica sobre la práctica como posibilidad de apropiarse críticamente de la realidad educativa, que no es estática sino que, por el contrario, constituye un movimiento dinámico y cambiante, en un permanente proceso dialéctico entre el hacer y el pensar sobre el hacer.

Reflexión-acción-reflexión se tornan indispensables en la formación docente, no sólo para modificar la práctica a partir del pensamiento, sino para generar nuevos pensamientos a partir de la práctica.

Según el mismo Freire (1997,p. 46), "una de las tareas más importantes de la práctica educativo-crítica es propiciar las condiciones para que los educandos en sus relaciones entre sí y de todos con el profesor o profesora puedan ensayar la experiencia profunda de asumirse". Y para poder asumirse, el educando debe reconocerse como un sujeto que es capaz de conocer y que quiere conocer en relación con otro sujeto igualmente capaz de conocer, el educador, para poder entre ambos posibilitar la tarea y el objeto de conocimiento.

El educador es sujeto de la educación, pero también el educando es sujeto de ese mismo proceso. Esto nos lleva a plantearnos una educación liberadora que implica criticar la forma de pensar de los seres humanos, de cómo reflexionan, procesan información, relacionan contenidos, resuelven problemas y crean cosas nuevas.

En este orden de ideas, la educación superior requiere un educador más humano y receptivo a los planteamientos e ideas de los educandos. Al respecto, FREIRE (1987, p 86) plantea que "...el educador ya no es sólo el que educa sino aquel que, en tanto educa, es educado a través del diálogo con el educando, quien, al ser educado, también educa. Así, ambos se transforman en sujetos del proceso en que crecen juntos y en el cual "los argumentos de la autoridad" ya no rigen. Proceso en el que ser funcionalmente autoridad requiere el estar siendo con las libertades y no contra ellas. (p. 86).

En palabras de Freire: "En una práctica educativa realmente democrática, nada mecanicista, radicalmente progresista, el educador o la educadora no pueden despreciar esas señales de rebeldía. Al contrario, al enseñar los contenidos indispensables, él o ella deben tomar la rebeldía de la mano, estudiarla como postura que ha de ser superada por una crítica, más comprometida, conscientemente politizada, metodológica y rigurosa". (FREIRE, 1997, p. 41) 
Ahora bien, cómo mantener vivo el gusto por la rebeldía, por la curiosidad, por la capacidad de arriesgarse, de aventurarse, de crear y de recrear. En este sentido considero que, en las aulas de educación superior, urge abandonar el dogmatismo y dar lugar a la interrogación, emancipación y concienciación; reforzar la capacidad crítica, la curiosidad, la no-sumisión, intentar convertirnos en sujetos de construcción y reconstrucción del saber. No perder de vista que el conocimiento tiene relación con la realidad, con el mundo. $Y$ aunque nunca estemos totalmente seguros de nuestras certezas, no admite soberbia; por el contrario, la incertidumbre es la apuesta a la esperanza. Se enseña y aprende el conocimiento existente, pero también se trabaja para la producción de un saber aún no existente. Enseñar, aprender, investigar es el camino.

\section{A PARTIR DE FREIRE ...}

Teniendo en cuenta los planteamientos de Freire, y la observación sistemática de la realidad actual en el proceso de formación docente, se pueden deducir algunas implicancias para la educación superior que los profesores no deberíamos perder de vista:

- Coherencia entre el decir y el hacer.

- Dar la voz a los estudiantes, tomando la realidad como punto de partida del acto de conocer.

- La horizontalidad en la comunicación, propiciando el dialogo.

- Asumir que la función del o la estudiante de educación superior no es adaptarse al sistema y sobrevivir si puede, sino que tiene el derecho de diferir, de proponer cambios, de hacer planteamientos, de disentir.

- Reconocer que enseñar exige rigor metodológico. Lo que exige que el o la docente enseñen a sus estudiantes a pensar correctamente, promuevan la lectura crítica, y a no estar demasiado seguros de nuestras propias certezas.

- Comprender que la enseñanza requiere de la investigación. En particular, tal como propone Freire, el o la docente tiene que percibirse como un investigador.

- Evitar cualquier tipo de discriminación, sea por la razón que fuere, aceptar que las personas tienen no solo la posibilidad, sino el derecho, de cambiar en sus concepciones y en sus apreciaciones.

- Comprender, que los actos educativos no son políticamente neutrales.

\section{Para tener en Cuenta...}

Algunas frases de Paulo Freire que merecen una consideración especial en el trabajo diario de la formación docente: 
DOI: $10.12957 /$ e-mosaicos.2017.30816

- El saber no radica en el "acumular conocimientos" sino en el aprender mediante la conciencia crítica.

- No existe desfase entre el enseñar y el aprender, pues ambos implican un descubrimiento propio y ajeno.

- El aprender implica percibir, repensar y sugerir.

- Enseñar exige respeto a los saberes de los educandos.

- Enseñar exige la corporización de las palabras por el ejemplo.

- Enseñar exige respeto a la autonomía del ser del educando.

- Enseñar exige seguridad, capacidad profesional y generosidad.

- Enseñar exige saber escuchar.

- Nadie es, si se prohíbe que otros sean.

- No hay palabra verdadera que no sea unión inquebrantable entre acción y reflexión.

- Decir la palabra verdadera es transformar al mundo.

- El estudio no se mide por el número de páginas leídas en una noche, ni por la cantidad de libros leídos en un semestre. Estudiar no es un acto de consumir ideas, sino de crearlas y recrearlas.

- Defendemos el proceso revolucionario como una acción cultural dialogada conjuntamente con el acceso al poder en el esfuerzo serio y profundo de concienciación.

- La ciencia y la tecnología, en la sociedad revolucionaria, deben estar al servicio de la liberación permanente de la HUMANIZACIÓN del hombre.

- La educación no cambia el mundo, cambia a las personas que van a cambiar el mundo

\section{A MODO DE CONCLUSIÓN...}

Analizadas las variables en relación a algunos indicadores, como porcentaje de atraso académico, alumnos que recursan las prácticas docentes entre dos y tres años, imposibilidad de aplicar la teoría abordada en las clases a la resolución práctica de situaciones, lleva indudablemente a replantearse la necesidad de poner a discusión el modelo de formación docente que hoy necesitamos.

En este sentido, es relevante reconocer la propuesta y la concepción educativa de Paulo Freire, ya que propone una relación entre las personas que participan en el proceso educativo, partiendo de la posibilidad de aprender y enseñar como relación dialéctica (sustentada en el diálogo), y una forma de mirar la relación entre la educación y la política que favorezca la toma de conciencia de las personas sobre su situación social y política, las causas que provocan y justifican ese estado y la identificación de posibilidades de liberación. En definitiva, la educación debe permitir al hombre contribuir en la transformación del mundo, ser crítico de su realidad y valorar su vivencia como algo lleno de valor real.

Además, es imperioso convertir el aula en un espacio científico. Es decir, integrar el procedimiento científico en el aula donde concurren educadores y 


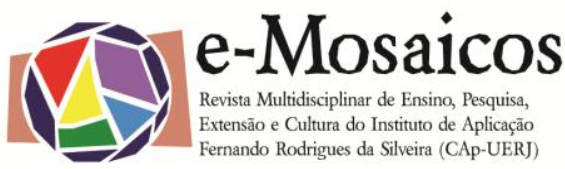

DOI: $10.12957 /$ e-mosaicos.2017.30816

educandos, ambos sujetos del conocimiento. Para ello, la tarea didáctica del profesor consiste en saber proponer -plantear- el problema de investigación frente a los estudiantes -los investigadores-, para que después de haber visto el objeto de estudio -el problema de investigación- se propongan investigarlo. En este aspecto, considero que es tema de debate y discusión la incumbencia de títulos que permite hoy en la Provincia de Buenos Aires que la mayor parte de los docentes sean generalistas y no existe la posibilidad de ingreso a quienes tienen títulos específicos de los profesorados que se dictan.

Definitivamente, hay que erradicar la educación bancaria para dar paso a la urgente necesidad de nuestros pueblos, de una docencia que incorpore la investigación.

Tal como sugiere Freire, tenemos que tomar al educando como sujeto del proceso educativo y no como objeto; superar la contradicción educador educando fundamentándonos en la relación de horizontalidad. Estas ideas se basan en su creencia de que tanto los maestros como los estudiantes tienen fortalezas y que el aprendizaje debe, y puede, ser recíproco. Así, sostiene que el educador debe llevar al sujeto que aprende a tomar conciencia de su relación con los demás, de sus posibilidades de realización como persona, de las condiciones de opresión en que se encuentra y de las posibilidades de emancipación que puede construir.

Me parece fundamental poder promover en los procesos educativos en los que participamos la coherencia y la ética. ¿Qué se requiere para ello? Según Freire, para lograr esa coherencia, el educador tiene que buscar siempre la coherencia, como un proceso permanente de perfección, buscando acercar lo que decimos y lo que hacemos, nuestros sueños y nuestras prácticas, todo lo cual exige humildad en el educador.

Recordando permanentemente que Freire criticó la transmisión autoritaria y memorística de los contenidos, que su pensamiento está profundamente cimentado en el concepto de libertad, concepto que pone al servicio de la transformación de los procesos educativos y sociopolíticos, que busca que las y los estudiantes y las y los docentes dejen de ser objetos pasivos de una historia estática y dogmática, para convertirse en sujetos responsables, capaces de conocer y de crear su propia historia.

Hoy encontramos en el pensamiento de Freire los cimientos que sustentan la posibilidad del cambio necesario para convertir los conocimientos de la formación docente en una propuesta de interjuego entre educandos y educadores que permita la interacción y la mejora.

La propuesta, aceptar el desafío, animarse a...

Paulo Freire nos enseña a mirar la realidad, a dialogar con ella, a conocerla para transformarla. Enseña que no es cuestión de repetir o copiar, que se trata de recuperar los sueños, los nuestros, el sentido verdadero de la educación y la utopía esperanzada del cambio. 


\section{RefERENCIAS Bibliográficas}

FREIRE, Paulo. Pedagogía de la autonomía, saberes necesarios para la práctica educativa. México: Siglo Veintiuno, S.A. de C.V., 1997.

FREIRE, Paulo. Pedagogía del oprimido. México DF: Siglo XXI, 1985.

FREIRE, Paulo. Pedagogía de la esperanza: un reencuentro con la "pedagogía del oprimido". Buenos Aires: Siglo XXI, 2006.

GADOTTI, Moacir. ¿Por qué continuar leyendo a Freire?. En: GADOTTI, Moacir; GOMEZ, Margarita; FREIRE, Lutgardes (Comps). Lecciones de Paulo Freire cruzando fronteras. experiencias que se completan. Buenos Aires: CLACSO, 2003.

ZEICHNER, Kenneth. Los profesores como profesionales reflexivos y la democratización de la reforma escolar. En: Volver a pensar la educación. Madrid: Morata, 1995. 